\title{
HUBUNGAN ANTARA RISIKO TERJADINYA KATARAK SEKUNDER DENGAN BERBAGAI TEKNIK OPERASI KATARAK DI RSUD dr.SAIFUL ANWAR MALANG PERIODE JANUARI - DESEMBER 2008
}

\section{Thalib Wifaaq}

Fakultas Kedokteran, Universitas Muhammadiyah Malang, J1. Bendungan Sutami 188 A Sumbersari malang, Lowokwaru, Kota Malang, 65145, Indonesia, (0341) 582060

\begin{abstract}
ABSTRAK
Angka kejadian katarak sekunder akibat sisa kapsul lensa anterior yang menyebabkan kekeruhan lensa posterior pasca bedah katarak masih tinggi. Gangguan penglihatan yang ditimbulkan oleh katarak sekunder bisa lebih buruk dari gangguan penglihatan sebelum operasi katarak. Tujuan penelitian ini untuk mengetahui hubungan antara risiko terjadinya katarak sekunder dengan berbagai teknik operasi katarak. Metode penelitian yang digunakan adalah observasional analitik dengan pendekatan cross sectional study menggunakan data rekam medis. Sampel yang diambil adalah total sampling pasien yang menderita katarak sekunder sebanyak 16 orang di RSUD dr.Saiful Anwar Malang periode Januari - Desember 2008. Penelitian dilakukan pada Januari - Februari 2010. Pasien yang mengalami katarak sekunder dengan teknik operasi EKEK sebanyak 11 orang, dan pasien katarak sekunder dengan teknik operasi fakoemulsifikasi sebanyak 5 orang. Data yang di dapat diolah dengan uji Chi-Square didapatkan nilai P (signifikansi) untuk teknik EKEK sebesar 0,280 (p > 0,05) dan nilai $\mathrm{P}$ (signifikansi) untuk teknik fakoemulsifikasi sebesar 0,280 ( $\mathrm{p}>0,05)$ yang berarti kedua teknik tersebut tidak ada hubungan yang signifikan dengan terjadinya katarak sekunder. Kesimpulan dari penelitian ini, antara risiko terjadinya katarak sekunder dengan berbagai teknik operasi katarak tidak berhubungan.
\end{abstract}

Kata Kunci: Katarak Sekunder dan Teknik Operasi Katarak.

\section{ABSTRACT}

The incidence of secondary cataract result from the rest of anterior lens that caused posterior lens opacity after cataract surgery was still high. Vision disorder of secondary cataract could be worst than before surgery. The purpose of this research was to examined the relationship between secondary cataract with surgical cataract technics. The method that had been used in this research was observational analytic through Cross Sectional study approach with medical record. We got 16 samples with secondary cataract in Saiful Anwar hospital Malang period January - December 2008. The research had been done in January - February 2010. Patients who had secondary cataract with ECCE technic were 11 persons, and patients who had sedondary cataract with phacoemulsification were 5 persons. The data was using Chi-Square test. The P-value (significancy) of ECCE technic was 0,280 and 0,280 for phacoemulsification.So, there was no significant relationship. The research conclude that there was no significant relationship between secondary cataract with surgical cataract technics.

Key words: Secondary Cataract and Surgical Cataract Technics

\section{PENDAHULUAN}

\section{Latar Belakang}

Katarak Sekunder adalah katarak yang terjadi akibat terbentuknya jaringan fibrosis pada sisa lensa yang tertinggal, paling cepat keadaan ini terlihat sesudah dua hari operasi Ekstraksi Katarak Ekstra Kapsuler (EKEK), dan penanaman lensa di segmen posterior. Atau, katarak yang terjadi sesudah suatu trauma yang memecah lensa (Ilyas, 2006).

Tingkat terjadinya katarak sekunder di dunia tahun 2002 pada tekhnik operasi katarak EKEK lebih tinggi dari teknik operasi fakoemulsifikasi yaitu 20,2\% dalam 1 tahun, $25 \%$ dalam 2 tahun serta 33,1\% dalam 3 tahun pasca operasi. Angka kejadian atau insidens kekeruhan kapsul posterior (posterior capsule opacification;PCO) semakin menurun dengan tekhnik fakoemulsifikasi, penggunaan materi Intra Ocular Lensa (IOL) yang lebih bersifat biocompatible serta IOL yang membantu menghambat proliferasi epitel lensa.
Schaumberg et al melaporkan angka kejadian PCO adalah sebesar 11,8\% dalam 1 tahun, 20,7\% dalam 2 tahun, serta $28,5 \%$ setelah 3 tahun pasca operasi (Soekardi I, Hutauruk JA, 2004).

Beberapa jenis teknik ekstraksi katarak yaitu inspirasi aspirasi lensa, Ekstraksi Katarak Intra Kapsular (EKIK), Ekstraksi Katarak Ekstra Kapsular (EKEK), dan teknik yang paling modern adalah fakoemulsifikasi. Pasca bedah katarak masih mempunyai resiko terjadinya katarak sekunder. Terjadi apabila reaksi radang yang diikuti dengan terbentuknya jaringan fibrosis sisa lensa anterior yang tertinggal pada permukaan lensa posterior maka keadaan ini disebut sebagai katarak sekunder. Tindakan bedah yang menimbulkan katarak sekunder adalah sisa ekstraksi linear dan ekstraksi lensa ekstrakapsular termasuk disini teknik ekstraksi katarak yang menggunakan teknik fakoemulsifikasi (Raseobala, 2008). 
Risiko terjadinya katarak sekunder akibat sisa kapsul lensa anterior yang menyebabkan kekeruhan lensa posterior sesuai dengan angka kejadian katarak sekunder pasca bedah katarak masih tinggi. Selain itu, gangguan penglihatan yang ditimbulkan oleh katarak sekunder bisa lebih buruk dari gangguan penglihatan sebelum operasi katarak. Data riset menyebutkan bahwa teknik operasi katarak yang masih diterapkan sampai saat ini belum bisa menghindari risiko terjadinya katarak sekunder (Rasoebala, 2008). Karena itu peneliti ingin memastikan apakah ada hubungan antara risiko terjadinya katarak sekunder dengan teknik ekstraksi katarak.

Angka kebutaan akibat katarak masih tinggi di kota Malang, untuk mengurangi kebutaan akibat katarak dan timbunan katarak, rumah sakit Saiful Anwar Malang sering melakukan pengobatan gratis terhadap pasien yang menderita katarak dengan melakukan operasi katarak, dan rumah sakit ini merupakan rumah sakit daerah yang mempunyai banyak data mengenai katarak dan operasi katarak. Sehingga penelitian ini akan dibuat berdasarkan data rekam medik penderita katarak sekunder yang mengalami operasi di rumah sakit Saiful Anwar Malang periode JanuariDesember 2008.

\section{Rumusan Masalah}

Apakah terdapat hubungan antara risiko terjadinya katarak sekunder dengan teknik operasi katarak di RSUD dr. Saiful Anwar Malang periode Januari - Desember 2008?

\section{Tujuan}

\section{Tujuan umum}

Mengetahui hubungan antara risiko terjadinya katarak sekunder dengan teknik pembedahan katarak.

\section{Tujuan khusus}

1. Mengetahui jumlah penderita katarak sekunder di RSUD dr. Saiful Anwar malang

2. Mengetahui karakteristik penderita katarak sekunder (usia, jenis kelamin, pekerjaan, diagnosa sebelum operasi, sisi mata yang terkena katarak)

3. Mengetahui dan membandingkan teknik pembedahan yang bisa meningkatkan risiko terjadinya katarak sekunder.

\section{METODOLOGI PENELITIAN}

\section{Desain Penelitian}

Desain penelitian yang dipilih adalah penelitian observasional analitik dengan pendekatan "cross sectional" yang bertujuan untuk menilai korelasi antara faktor resiko terjadinya katarak sekunder dengan teknik bedah katarak.

\section{Tempat dan Waktu Penelitian}

Penelitian dilakukan di RSUD dr. Saiful Anwar Malang. Waktu penelitiannya Januari- februari 2010. Populasi, Sampel dan Sampling

Populasi penelitian ini adalah seluruh pasien yang menderita katarak sekunder di RSUD dr. Saiful Anwar Malang Periode Januari - Desember 2008.
Sampel yang digunakan pada penelitian ini adalah pasien yang menderita katarak sekunder dan pasien pasca operasi katarak sebagai sampel kontrol periode Januari Desember 2008 di RSUD dr. Saiful Anwar Malang.

Sampling. Teknik Pengambilan Sampling yang digunakan pada penelitian ini adalah total sampling.

\section{Kriteria inklusi dan eksklusi}

1. Kriteria inklusi: Pasien yang menderita katarak sekunder

2. Kriteria eksklusi:1. Pasien katarak sekunder pasca trauma lensa, 2. Pasien katarak sekunder dengan Diabetes Melitus, 3. Pasien katarak sekunder dengan riwayat pemakaian steroid jangka panjang

\section{Alur Penelitian}

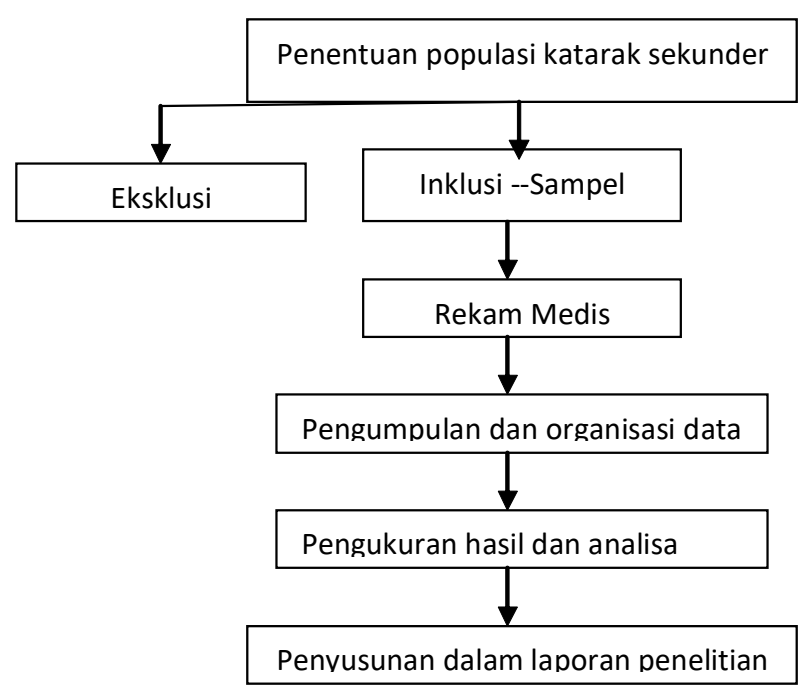

\section{Identifikasi Variabel}

1. Variabel bebas : Variabel bebas pada penelitian ini adalah teknik bedah katarak EKEK dan fakoemulsifikasi

2. Variabel tergantung: Variabel tergantung pada penelitian ini adalah katarak sekunder

\section{Definisi Operasional}

Katarak Sekunder : katarak yang diperoleh dari data rekam medis dimana terjadi kekeruhan lensa posterior akibat terbentuknya jaringan fibrosis pada lensa setelah operasi katarak.

Teknik Operasi Katarak : suatu teknik operasi pengambilan katarak yaitu inspirasi aspirasi lensa, Ekstraksi Katarak Intra Kapsular (EKIK), Ekstraksi Katarak Ekstra Kapsular (EKEK), dan fakoemulsifikasi yang diambil dari data rekam medik.

\section{Instrumen Penelitian}

Alat dan bahan yang digunakan adalah data sekunder dari rekam medis pasien dengan katarak sekunder di RSUD dr. Saiful Anwar Malang periode Januari - Desember 2008

\section{Pengolahan Data dan Analisis Data}

1. Prosedur pengambilan dan Pengumpulan Data. Data penelitian diperoleh dari data sekunder rekam medis pasien dengan katarak sekunder di RSUD dr.Saiful Anwar Malang. 
2. Analisa Data. Untuk mengetahui prevalensi data dianalisa menggunakan tabel distribusi dan untuk mengetahui hubungan antara katarak sekunder dengan teknik operasi katarak menggunakan uji hipotesis asosiatif dengan menggunakan uji Chi-Square disajikan dalam bentuk tabel frekuensi distribusi.

\section{HASIL PENELITIAN DAN ANALISA DATA}

Berdasarkan hasil penelitian data rekam medis pasien yang datang ke RSUD dr.Saiful Anwar Malang periode Januari - Desember 2008 yang mengalami katarak sekunder, didapatkan 16 sampel. Memiliki distribusi sampel berdasarkan karakteristik usia, jenis kelamin, dan pekerjaan. Analisa data menggunakan uji Chi-Square.

\section{Distribusi Sampel Penelitian}

1. Distribusi Sampel Penelitian Berdasarkan Karakteristik Usia

Berdasarkan hasil penelitian diperoleh data sampel penelitian berdasarkan karakteristik usia dapat dilihat pada tabel 5.1

Tabel 3.1 Distribusi Sampel Berdasarkan Karakteristik Usia

\begin{tabular}{|c|c|c|}
\hline Usia & Frequensi & Persentase \\
\hline $31-45$ tahun & 1 & $6,3 \%$ \\
\hline $46-60$ tahun & 8 & $50 \%$ \\
\hline $61-75$ tahun & 6 & $37,5 \%$ \\
\hline $76-90$ tahun & 1 & $6,3 \%$ \\
\hline Total & 16 & $100 \%$ \\
\hline
\end{tabular}

Sumber: Data Primer yang diolah dengan SPSS

Tabel 3.1 menunjukkan data mengenai frekuensi penderita yang menderita katarak sekunder di RSUD dr.Saiful Anwar periode Januari - Desember 2008 berdasarkan usia, dimana didapatkan penderita terbanyak pada usia $46-60$ tahun sebanyak 8 orang atau sebesar $50 \%$. Kelompok umur yang mengalami katarak sekunder pada urutan kedua ada pada kelompok usia 61 - 75 tahun sebanyak 6 orang atau sebesar 37,5 \%, urutan ketiga ada pada kelompok usia 31 - 45 tahun dan kelompok usia 76 - 90 tahun sebanyak 1 orang atau sebesar $6,3 \%$.

2. Distribusi Sampel Penelitian Berdasarkan Karakteristik Jenis Kelamin

Berdasarkan hasil penelitian diperoleh data sampel berdasarkan karakteristik jenis kelamin, dapat dilihat pada Tabel 5.2

\section{Tabel 3.2 Distribusi Sampel Penelitian Karakteristik Jenis Kelamin}

\begin{tabular}{|c|c|c|}
\hline Jenis Kelamin & Frekuensi & Persentase \\
\hline Laki-laki & 9 & $56,3 \%$ \\
\hline Perempuan & 7 & $43,8 \%$ \\
\hline Total & 16 & $100 \%$ \\
\hline
\end{tabular}

Sumber: Data Primer yang diolah dengan SPSS

Tabel 3.2 didapatkan bahwa data mengenai frekuensi penderita yang mengalami katarak sekunder di RSUD dr.Saiful Anwar Malang periode Januari - Desember 2008 berdasarkan jenis kelamin terbanyak adalah laki-laki yaitu 9 orang atau sebesar $56,3 \%$ dan urutan kedua perempuan yaitu 7 orang atau sebesar $43,8 \%$.
3. Distribusi Sampel Penelitian Berdasarkan Karakteristik Pekerjaan

Berdasarkan hasil penelitian diperoleh data sampel penderita yang mengalami katarak sekunder di RSUD dr.Saiful Anwar Malang periode Januari - Desember 2008. Dapat dilihat pada Tabel 5.3.

\section{Tabel 3.3 Distribusi Sampel Penelitian Berdasarkan Karakteristik Pekerjaan}

\begin{tabular}{|c|c|c|}
\hline Pekerjaan & Frekuensi & Persentase \\
\hline IRT & 4 & $25 \%$ \\
\hline Wiraswasta & 4 & $25 \%$ \\
\hline Petani & 1 & $6,3 \%$ \\
\hline Buruh & 1 & $6,3 \%$ \\
\hline PNS & 4 & $25 \%$ \\
\hline Pedagang & 2 & $12,5 \%$ \\
\hline Total & 16 & $100 \%$ \\
\hline
\end{tabular}

Sumber: Data Primer yang diolah dengan SPSS

Tabel 3.3 didapatkan bahwa kelompok pekerjaan tertinggi adalah ibu rumah tangga, wiraswasta, dan pegawai negeri sipil sebanyak 4 orang atau sebesar $25 \%$, kelompok pekerjaan urutan kedua adalah pedagang sebanyak 2 orang atau sebesar $12,5 \%$, urutan ketiga adalah petani dan buruh dengan jumlah masing-masing sebanyak 1 orang atau sebesar $6,3 \%$.

\section{Hubungan Katarak Sekunder dengan Berbagai Teknik Operasi Katarak}

Uji statistik dilakukan untuk menganalisis hubungan antara risiko terjadinya katarak sekunder dengan berbagai teknik operasi katarak. Teknik operasi katarak yang dimaksud adalah teknik opersi EKEK dan fakoemulsifikasi. Teknik operasi katarak ini diuji dengan menggunakan uji Chi-Square menggunakan tabel $2 \mathrm{x} 2$.

Tabel 3.4 menggambarkan hasil tabel silang (crosstabs) terlihat bahwa pasien katarak sekunder dengan teknik operasi EKEK sebanyak 11 orang, dan pasien katarak sekunder dengan teknik operasi fakoemulsifikasi sebanyak 5 orang. Pasien yang tidak mengalami katarak sekunder dengan teknik operasi katarak EKEK sebanyak 8 orang dan pasien yang tidak mengalami katarak sekunder dengan teknik operasi fakoemulsifikasi sebanyak 8 orang. Pasien yang tidak menderita katarak sekunder ini bertindak sebagai kontrol.

Tabel 3.4 Crosstabs Antara Katarak Sekunder dengan Teknik Operasi Katarak

\begin{tabular}{|c|c|}
\hline Teknik Operasi & $\begin{array}{c}\text { Taraf Signifikansi (2- } \\
\text { sided) }\end{array}$ \\
\hline EKEK & 0.280 \\
\hline Fakoemulsifikasi & 0.280 \\
\hline
\end{tabular}

Sumber: Data Primer yang diolah dengan SPSS

Hasil pengujian dengan menggunakan uji Chi-Square tersebut dapat disusun dalam bentuk tabel sebagai berikut:

Untuk menguji adanya pengaruh antara katarak sekunder dengan teknik EKEK dan fakoemulsifikasi, maka digunakan uji Chi-Square sebagai test independency. Berdasarkan tabel 3.5 pada teknik operasi EKEK didapatkan hasil uji 
Chi-Square dengan taraf signifikansi sebesar 0,280 untuk 2sided dan teknik operasi fakoemulsifikasi didapatkan hasil uji Chi-Square dengan taraf signifikansi sebesar 0,280 untuk 2sided. Dimana nilai taraf signifikansi kedua teknik tersebut lebih besar dari alpha 0,05, sehingga dari data tersebut dapat disimpulkan bahwa antara risiko terjadinya katarak sekunder dengan berbagai teknik operasi katarak tidak mempunyai hubungan yang signifikan.

\section{Tabel 3.5 Uji Chi-Square Antara Katarak Sekunder dengan Berbagai Teknik Operasi Katarak}

\begin{tabular}{|c|c|c|c|}
\hline Teknik Operasi & EKEK & Fakoemulsifikasi & Total \\
\hline Katarak sekunder & 11 & 5 & 16 \\
\hline Non Katarak Sekunder & 8 & 8 & 16 \\
\hline Total & 19 & 13 & 32 \\
\hline
\end{tabular}

Sumber: Data Primer yang diolah dengan SPSS

\section{DISKUSI}

Penelitian ini dilakukan secara observasional analitik pada data rekam medik pasien yang mengalami katarak sekunder di RSUD dr.Saiful Anwar Malang periode Januari - Desember 2008 dengan jumlah sampel penelitian 16 orang. Penelitian ini bertujuan untuk mengetahui hubungan antara terjadinya katarak sekunder dengan berbagai teknik operasi katarak dan mengetahui teknik pembedahan yang bisa meningkatkan risiko terjadinya katarak sekunder. Selain itu juga disertakan data karakteristik pasien meliputi usia, jenis kelamin dan pekerjaan.

Berdasarkan hasil penelitian pasien yang telah mengalami katarak sekunder di RSUD dr.Saiful Anwar periode Januari - Desember 2008 didapatkan penderita terbanyak pada rentang usia $46-60$ tahun yaitu 8 orang atau sebesar $50 \%$. Dan jenis kelamin terbanyak adalah laki-laki yaitu 9 orang atau $56,3 \%$. Sedangkan untuk distribusi pekerjaan penderita katarak sekunder terbanyak pada ibu rumah tangga, wiraswasta dan pegawai negeri sipil yaitu 4 orang atau sebesar $25 \%$. Belum ada penelitian atau teori sebelumnya yang menyebutkan hubungan antara usia, jenis kelamin, dan pekerjaan dengan katarak sekunder. Hal ini karena usia, jenis kelamin, dan pekerjaan bukan merupakan faktor risiko dari katarak sekunder.

Berdasarkan teori, terdapat beberapa teknik ekstraksi katarak untuk melakukan terapi katarak yaitu inspirasi aspirasi lensa, Ekstraksi Katarak Intra Kapsular (EKIK), Ekstraksi Katarak Ekstra Kapsular (EKEK), dan teknik yang paling modern adalah fakoemulsifikasi. Pasca bedah katarak masih mempunyai risiko terjadinya katarak sekunder. Katarak terjadi apabila reaksi radang yang diikuti dengan terbentuknya jaringan fibrosis sisa lensa yang tertinggal maka keadaan ini disebut sebagai katarak sekunder. Tindakan bedah yang menimbulkan katarak sekunder adalah sisa ekstraksi linear dan ekstraksi lensa ekstrakapsular termasuk disini teknik ekstraksi katarak yang menggunakan teknik fakoemulsifikasi (Raseobala, 2008).

Teknik inspirasi aspirasi lensa juga secara teori mempunyai risiko terjadinya katarak sekunder, namun berdasarkan data rekam medis, teknik ini sudah ditinggalkan. Teknik operasi katarak yang menyisakan kapsul posterior lensa mempunyai risiko terjadinya katarak sekunder. Pada tindakan bedah lensa dimana terjadi reaksi radang yang berakhir dengan terbentuknya jaringan fibrosis sisa lensa yang tertinggal. Setelah operasi epitel lensa subkapsuler yang tersisa melakukan regenerasi serat lensa (epitel subkapsuler berproliferasi dan membesar) sehingga memberikan gambaran busa sabun atau telur kodok pada kapsul posterior disebut juga dengan mutiara elsching atau Elsching Pearl. Lapisan epitel yang berproliferasi tersebut mungkin menghasilkan banyak lapisan sehingga menimbulkan kekeruhan. Sel ini mungkin juga mengalami diferensiasi miofibroblastik. Kontraksi serat ini menimbulkan banyak kerutan kecil di kapsul posterior yang menimbulkan distorsi penglihatan. Cincin Soemmering juga dapat timbul sebagai kapsul anterior yang pecah dan traksi kearah pinggir melekat pada kapsul posterior, meninggalkan daerah yang jernih di tengah, dan membentuk gambaran cincin. Pada cincin ini tertimbun serabut lensa epitel yang berproliferasi. Semua faktor ini dapat menyebabkan penurunan ketajaman penglihatan seteleh EKEK (Ilyas,2006).

Hasil penelitian diperoleh pada teknik operasi EKEK terdapat 11 orang dengan katarak sekunder dan pada teknik operasi fakoemulsifikasi didapatkan 5 orang mengalami katarak sekunder. Dari hasil penelitian dengan uji Chi-Square tidak didapatkan hubungan antara katarak sekunder dengan berbagai teknik operasi katarak. Tetapi dari data analisa ini tidak menutup kemungkinan pasien yang mengalami katarak sekunder akan bertambah dikarenakan semakin lama jangka waktu pasca operasi semakin besar kemungkinan terjadinya katarak sekunder, sesuai dengan data hasil penilitian teknik operasi EKEK dan fakoemulsifikasi yang dipaparkan oleh Soekardi dan Hutauturuk JA. Menurut Soekardi dan Hutauruk JA tingkat terjadinya katarak sekunder di dunia tahun 2002 pada tekhnik operasi katarak EKEK lebih tinggi dari teknik operasi fakoemulsifikasi yaitu 20,2\% dalam 1 tahun, 25\% dalam 2 tahun serta 33,1\% dalam 3 tahun pasca operasi. Schaumberg et al melaporkan angka kejadian PCO adalah sebesar $11,8 \%$ dalam 1 tahun, 20,7\% dalam 2 tahun, serta $28,5 \%$ setelah 3 tahun pasca operasi (Soekardi I, Hutauruk JA, 2004).

Perbedaan hasil penelitian ini dengan teori dan penelitian-penelitian sebelumnya bisa jadi disebabkan karena kemungkinan pasien mengalami katarak sekunder pasca operasi katarak tetapi pasien tidak kembali berobat di tempat yang sama sehingga tidak didapatkan data yang cukup mengenai katarak sekunder. Faktor lainnya bisa disebabkan karena waktu terjadinya katarak sekunder lebih dari 1 tahun pasca operasi, sedangkan waktu penelitian yang digunakan hanya 1 tahun. Perbedaan hasil penelitian juga bisa disebabkan karena keterampilan para tenaga medis dalam hal ini dokter spesialis mata dalam memilih teknik EKEK maupun fakoemulsifikasi..Dalam penelitian ini tidak dapat diketahui teknik operasi mana yang bisa meningkatkan risiko terjadinya katarak sekunder oleh karena diperoleh hasil tidak ada hubungan yang signifikan antara terjadinya katarak sekunder dengan berbagai teknik operasi katarak. Secara teori teknik yang dapat meningkatkan risiko terjadinya katarak sekunder adalah inspirasi aspirasi lensa, Ekstraksi Katarak Ekstra Kapsular (EKEK), dan fakoemulsifikasi (Ilyas,2006).

Penelitian ini tidak mecantumkan dan meneliti mengenai langkah-langkah dalam setiap teknik operasi. 
Padahal dalam setiap langkah akan menentukan prognosa katarak sekunder. Jadi disarankan untuk penelitian selanjutnya untuk memasukkan langkah-langkah dalam setiap teknik operasi. Angka kejadian atau insidens kekeruhan kapsul posterior (posterior capsule opacification;PCO) semakin menurun dengan tekhnik fakoemulsifikasi, penggunaan materi Intra Ocular Lensa (IOL) yang lebih bersifat biocompatible serta IOL yang membantu menghambat proliferasi epitel lensa (Soekardi I, Hutauruk JA, 2004).

\section{KESIMPULAN DAN SARAN}

Berdasarkan hasil penelitian yang telah dilakukan, maka dapat ditarik kesimpulan sebagai berikut:

1. Pasien yang mengalami katarak sekunder pada teknik operasi EKEK sebanyak 68,7\% dan teknik operasi fakoemulsifikasi sebanyak 31,3\%.

2. Berdasarkan karakteristik penderita yang menderita katarak sekunder di RSUD dr.Saiful Anwar Malang periode Januari - Desember 2008 didapatkan:

a. Distribusi usia terbanyak adalah pada kelompok usia 46 - 60 tahun

b. Sebagian besar merupakan laki-laki

c. Distribusi pekerjaan terbanyak adalah sebagai ibu rumah tangga, pegawai negeri sipil dan wiraswasta.

3. Berdasarkan hasil penelitian tidak didapatkan hubungan antara risiko terjadinya katarak sekunder dengan teknik operasi katarak.

\section{DAFTAR PUSTAKA}

American Academy of Ophthalmology,2003, Lens and Cataract Section 11, The eye MD association, San Francisco.

A.R Elkington, PT Khaw, 2000, Petunjuk Penting Kelainan Mata, EGC, Jakarta

Burhanuddin, Katarak dan Kebutaan Mata, Juni 2004, Available from URL http://www.infomedika.com diakses 3 desember 2007

Cokro, Jumlah Orang Buta di Indonesia Terus Naik, 15 November 2006, availableFrom URL http://www. mediaindonesia-online.com diakses 14 april

2007

Ilyas, Sidarta, 2005, Ilmu Penyakit Mata, edisi ke-3, cetakan ke2, Balai Penerbit FK UI. Jakarta

Ilyas, Sidarta, editor, 2002, Ilmu Penyakit Mata, edisi ke-2, Sagung Seto, Jakarta

Ilyas, Sidarta, Editor, 2006, Katarak, edisi 2, EGC,Jakarta

Indrayanti, Ana, Mata Sehat Bebas Katarak, Desember 2006, Availabel from URL http://www.pikiranrakyat.com diakses tanggal 21 april 2007

Iwan. Bedah Katarak, Januari 2009, Available from URL http://www.kintonmultyply. Diakses tanggal 19 oktober 2009.

James,Bruce. Chew, Chris. Bron, Anthony, 2006, Oftalmologi, edisi 9, Erlangga. Jakarta

Jansirani, Ananthanaryanan, 2004, Oftalmolog, EGC, Jakarta

Notoadmodjo,2005, Metodologi Penelitian Kesehatan, Rineka Cipta.Jakarta
Poluan, Henry. Kebutaan Akibat Katarak, 2003, Available from URL : http://www.sinarharapan.co.id/iptek/ kesehatan/index diakses tanggal 3 desember 2009

Raseobala, Katarak dan Ekstraksi Katarak, Available from URL www.ilmukedokteran.net Diakses tanggal 23 oktober 2009

Sanders, Elizabeth MG, 2000, Gangguan Mata yang Menyertai Penyakit Sistemik, Widya medika. Jakarta

Shock JP, Harper RA, 1995, General of Ophthalmology edition 14, Lange Medical Publication, Los Angeles.

Soekardi I, Hutauturuk JA, 2004, Transisi Menuju Fakoemulsifikasi: langkah-langkah Menguasai Teknik dan Menghindari Komplikasi, Granit. Jakarta

Sulistya, Budi T, 2006, Lensa dan Keratoplasti, Malang, FKUB

Sutrisno, Waspadai Kebutaan Akibat Katarak, 30 November 2005, Available from URL : http://www.balipost.co.id diakses 21 april 2007

Vaughan DG, Asbury Taylor, 2000, Oftalmologi Umum, edisi 14, Widya medika. Jakarta

Widjaya, Nana, Katarak Sekunder, Available from URL www.mediamedika.net Diakses tanggal 23 oktober 2009 